\title{
LOS PROCESOS DE ÚNICA INSTANCIA EN EL CÓDIGO GENERAL DEL PROCESO: LA GARANTÍA CONSTITUCIONAL DEL DEBIDO PROCESO Y LA DOBLE INSTANCIA*
}

\author{
Milton César Jiménez Ramírez** \\ Diego Armando Yáñez Meza****
}

\author{
Fecha de recepción: 1 de febrero de 2016 \\ Fecha de evaluación: 19 de octubre de 2016 \\ Fecha de aprobación: 14 de noviembre de 2016 \\ Artículo de investigación
}

DOI: http://dx.doi.org/10.18359/prole.2725

Forma de citación: Jiménez, M.C. \& Yáñez, D.A. (2017). Los procesos de única instancia en el Código General del Proceso: la garantía constitucional del debido proceso y la doble instancia. Revista Prolegómenos Derechos y Valores, 20, 39, 87-104. DOI: http://dx.doi.org/10.18359/prole.2725

\section{Resumen}

En el presente artículo se evalúa la figura de la única instancia en la ley 1564/2012 o Código General del Proceso, con la finalidad de determinar si estos procesos son una infracción a la garantía constitucional del debido proceso y la doble instancia. Esta ley en sus artículos 17, 19 y 21, estableció la competencia de los jueces civiles municipales, civiles de circuito y de familia en procesos de única instancia, disposiciones que pueden constituirse como una infracción a la garantía procesal y constitucional del debido proceso y la doble instancia, desde la lectura del artículo 31 de la Constitución Política de 1991. Esta investigación es de tipo analítico-conceptual, aplica el método cualitativo y es de corte documental bibliográfico.

\section{Palabras clave:}

Única instancia, doble instancia, Código General del Proceso, descongestión judicial, test de proporcionalidad.

Artículo producto de investigación del proyecto denominado "Análisis de la figura de la única instancia en la ley 1564 de 2012: la garantía procesal y constitucional del debido proceso y la doble instancia", desarrollado por el investigador Milton César Jiménez Ramírez, en la Facultad de Ciencias Jurídicas y Sociales de la Universidad de Caldas (Manizales, Colombia) y Diego Armando Yáñez Meza, en la Facultad de Derecho, Ciencia Política y Sociales y Centro de Investigaciones de la Universidad Libre seccional Cúcuta (Cúcuta, Colombia). El proyecto se ejecutó entre julio y diciembre de 2015.

* Abogado por la Universidad de Caldas (Manizales, Colombia), especialista en Derecho Constitucional de la Universidad Nacional de Colombia (Bogotá, Colombia). Magíster en Derecho Público por la Universidad Externado de Colombia (Bogotá, Colombia); doctorando en Derecho por la Universidad Carlos III de Madrid (Madrid, España); docente investigador del Programa de Derecho y director de la especialización en Derecho Administrativo de la Facultad de Ciencias Jurídicas y Sociales de la Universidad de Caldas. Miembro del Grupo de Investigación en Estudios Jurídicos y Socio Jurídicos de la misma universidad. Correo electrónico: milton.jimenez@ucaldas.edu.co

*** Abogado por la Universidad Libre seccional Cúcuta (Cúcuta, Colombia); especialista en Derecho Público. Magíster en Derecho Administrativo, Universidad Externado de Colombia (Bogotá, Colombia). Magíster (C) en Derecho Procesal Contemporáneo, Universidad de Medellín (Medellín, Colombia). Autor de libros y artículos de investigación. Director Grupo de Investigación en Derecho Público y del Semillero de Investigación en Derecho Administrativo "Louis Antoine Macarel" de la Universidad Libre seccional Cúcuta. Docente en pregrado y posgrado. El autor agradece la contribución al proceso investigativo como auxiliares de investigación a los estudiantes Daniela Carolina Laguado Salazar, Aldis Nebai Becerra Garza y Ana Milena Chaustre González. Correo electrónico: diego.yanez@unilibrecucuta.edu.co 


\title{
THE PROCESSES OF SINGLE INSTANCE IN THE GENERAL CODE OF THE PROCESS: THE CONSTITUTIONAL GUARANTEE OF THE DUE PROCESS AND THE DOUBLE INSTANCE
}

\begin{abstract}
Summary
In this article the figure of the single instance is evaluated in law 1564/2012 or General Code of the Process, in order to determine if these processes are a violation of the constitutional guarantee of the due process and the double instance. This law, in its articles 17, 19 and 21, established the competence of civil municipal judges, civil of circuit and of family in processes of single instance, provisions that can constitute an infringement to the procedural and constitutional warranty of the due process and the double instance, from the reading of the article 31 of the Political Constitution of 1991. This research is analytical-conceptual type, applies the qualitative method and is documentary bibliographic style.
\end{abstract}

\section{Key words:}

Single instance, double instance, General Code of the Process, judicial relief, proportionality test.

\section{OS PROCESSOS DE INSTÂNCIA ÚNICA NO CÓDIGO GERAL DO PROCESSO: A GARANTIA CONSTITUCIONAL DO DEVIDO PROCESSO E DA DUPLA INSTÂNCIA}

\begin{abstract}
Resumo
No presente artigo é avaliada a figura da instância única na lei 1564/2012 ou Código Geral do Processo, com a finalidade de determinar se estes processos são uma infração à garantia constitucional do devido processo e da dupla instância. Esta lei em seus artigos 17, 19 y 21, estabeleceu a competência dos juízes civis municipais, das varas civis e de família em processos de instância única, disposições que podem constituir uma infração à garantia processual e constitucional do devido processo e da dupla instância, desde a leitura do artigo 31 da Constituição Política de 1991. Esta pesquisa é de tipo analítico-conceitual, aplica o método qualitativo e é de corte documental bibliográfico.
\end{abstract}

\section{Palavras-chave:}

Instância única, dupla instância, Código Geral do Processo, descongestionamento judicial, teste de proporcionalidade.

Porque todo orden descansa sobre una decisión, y también el concepto de orden jurídico, que irreflexivamente suele emplearse como cosa evidente, cobija en su seno el antagonismo de los dos elementos dispares de lo jurídico. También el orden jurídico, como todo orden, descansa en una decisión, no en una norma. Schmitt (2009, p. 16)

\section{Introducción}

El presente artículo busca evaluar la figura de la única instancia -definida en la ley 1564/2012 o Código General del Proceso (CGP)-, con la finalidad de determinar si el trámite que se exige para estos procesos constituye una infracción a 
la garantía procesal y constitucional del debido proceso y la doble instancia.

Para el desarrollo de esta investigación es menester considerar la efectividad de los derechos fundamentales en el contexto de la implementación de la teoría general del derecho denominada neoconstitucionalismo, teoría que se introdujo en Colombia desde la expedición de la Constitución Política de 1991 y que se ha consolidado a partir del trabajo jurisprudencial de la Corte Constitucional, representando un cambio sustancial en el sistema de fuentes $y$ el quehacer judicial, en donde se observa un marcado activismo mediante el fenómeno de la constitucionalización del derecho y en donde todas las áreas del derecho tienen que cimentarse en los preceptos constitucionales. Por consiguiente, el derecho procesal en todos sus conceptos, instituciones y figuras, debe apoyarse en las disposiciones constitucionales, especialmente en los derechos fundamentales como parte dogmática de la norma de normas ${ }^{1}$.

Para contextualizar el neoconstitucionalismo, es relevante mencionar que en este, el juez interpreta de manera abierta la Constitución con el propósito de asegurar la tutela efectiva de los derechos y, por esta razón, resulta extraña la figura de la única instancia dentro del ordenamiento jurídico. Así pues, esta figura no tiene fundamento, máxime cuando en el marco del nuevo derecho, cada vez más creciente en el constitucionalismo latinoamericano y colombiano, se habla de la expansión de las garantías.

Ahora bien, es en esta teoría jurídica del neoconstitucionalismo en la que se enmarca el estudio de las garantías constitucionales del debido proceso

\footnotetext{
El neoconstitucionalismo como categoría base del artículo o de su marco teórico, parte del concepto que se ha enunciado. De esta forma, si bien existen controversias en la doctrina nacional $e$ internacional sobre este canon, por ejemplo a partir de las tesis de profesores como García Amado (2009) o Laporta (2007), y su vigencia se cuestiona frente a serios sucesos que desprestigian la justicia constitucional, el concepto tiene plena validez desde la jurisprudencia de la Corte Constitucional colombiana.
}

y la doble instancia; derechos fundamentales que pueden vulnerarse con el desarrollo de los procesos de única instancia establecidos en los artículos 17, 19 y 21 del CGP. Así pues, debe tenerse en cuenta que "los derechos fundamentales son el ejemplo más claro de principios que tenemos en el ordenamiento jurídico" (Bernal, 2005, p. 96); principios que cimientan todo el ordenamiento jurídico colombiano mediante la aplicación de sus tres principales funciones: creativa, interpretativa e integradora.

Como se observa, los principios toman gran valor debido a que se presentan de manera transversal a todo el ordenamiento jurídico (Alexy, 1997), siendo las normas jurídicas que orientan la creación de las demás disposiciones. Por consiguiente, el derecho no puede reducirse a una mera aplicación silogística de la norma jurídica al caso concreto; por el contrario, debe abarcar diferentes disposiciones tendientes a materializar el principio que Hernán Valencia (2007, p. 216) denomina como "sumo": la justicia.

De este modo, habiendo transcurrido 25 años desde la convocatoria a una Asamblea Nacional Constituyente, la Carta Política antes que negar, afirma la validez y la vigencia de las disposiciones contenidas en los códigos y leyes, y estos a su vez, expresa o tácitamente, se refieren a los postulados axiológicos y principialísticos de aquella, sin perjuicio de ser, por regla general, el desarrollo normativo de la Constitución. Ante este panorama, el CGP armonizó sus contenidos con los preceptos de la Constitución de 1991.

Es así como la garantía del debido proceso y la doble instancia son derechos protegidos en la Constitución y en la Convención Interamericana de Derechos Humanos, tanto así que se utilizó esta última en los debates para la aprobación del acto legislativo 02/2015 o reforma del equilibrio de poderes como argumento para criticar el proceso de única instancia para los congresistas; sin embargo, es de revisar si al margen de la apreciación nacional se permite crear excepciones legítimas al principio, o si estas deben crearse en circunstancias determinadas. 
En este panorama principialístico, cabe mencionar que la Corte Constitucional en su sentencia T-406/1992 explica el concepto del Estado social de derecho, señalando a los principios constitucionales como la base axiológica del ordenamiento jurídico colombiano. Sobre el tema, la corporación manifiesta:

Uno de los pilares del Estado social de derecho se encuentra en el concepto de derecho fundamental. Dos notas esenciales de este concepto lo demuestran. En primer lugar su dimensión objetiva, esto es, su trascendencia del ámbito propio de los derechos individuales hacia todo el aparato organizativo del Estado. Más aún, el aparato no tiene sentido si no se entiende como mecanismo encaminado a la realización de los derechos. En segundo lugar, y en correspondencia con lo primero, la existencia de la acción de tutela, la cual fue establecida como mecanismo de protección inmediata de los derechos frente a todas las autoridades públicas y con posibilidad de intervención de la Corte Constitucional para una eventual revisión de las decisiones judiciales, que sirva para unificar criterios de interpretación (sentencia T-406/1992).

Así pues, esta sentencia declaró que los derechos fundamentales al igual que todas las normas constitucionales, deben ser emanación directa de los valores y los principios constitucionales (Dworkin, 1980); por tal razón, se habla por ejemplo de principios o de derechos del debido proceso, doble instancia, entre otros.

Para la ejecución de esta investigación se formuló como objetivo general el siguiente: determinar si la única instancia definida en el CGP constituye una infracción a los principios procesales y constitucionales del debido proceso y la doble instancia. También se planteó una hipótesis que a continuación se menciona:

La única instancia se ha concebido como una forma de descongestionar el aparato de administración de justicia, y de no brindar mayores tratamientos jurídicos a asuntos que se estiman como de menor importancia por parte del legislador. Puede ser esta situación discriminatoria, y violatoria del derecho a la igualdad, máxime cuando estos asuntos son los de mayor ocurrencia en la población menos favorecida. Además, la figura de la única instancia en la ley 1564/2012 puede estar vulnerando la garantía procesal y constitucional del debido proceso y la doble instancia.

\section{A. Problema de investigación}

¿Cuál es el resultado de la aplicación del test de proporcionalidad en los procesos de única instancia regulados en el CGP, frente al propósito de descongestión judicial, celeridad y la garantía constitucional del debido proceso y la doble instancia?

\section{B. Metodología}

Esta investigación es de tipo descriptivo, analíticoconceptual, correlacional y explicativo, porque se dirige a examinar específicas instituciones, su concepto, desarrollo en el sistema de fuentes y su contraste con otras variables, identificándose diversos criterios aplicables para por último perfilar el que se encuentra acorde con los contenidos constitucionales.

El método que se empleó fue el descriptivo y de corte documental o método bibliográfico, que se ubica en las investigaciones dogmáticas, siendo aplicado para lograr la consecución de los objetivos trazados. Lo anterior, debido a que se quiso ahondar en el estudio de la esencia de los derechos del debido proceso y doble instancia en relación con su posible vulneración en el conocimiento en única instancia de asuntos civiles y de familia contemplados en los artículos 17 , 19 y 21 del Código, para llegar a evidenciar el impacto que tendrá en el derecho procesal y constitucional colombiano este tema de gran valía académica. Haciendo referencia al método documental o bibliográfico, se tiene que

(...) consiste en la captación por parte del investigador de datos aparentemente 
desconectados, con el fin de que a través del análisis crítico se construyan procesos coherentes de aprehensión del fenómeno y de abstracción discursiva del mismo para así valorar o apreciar nuevas circunstancias (Botero, 2003, p. 112).

En consecuencia, los documentos y la bibliografía tienen gran significación en la investigación documental, debido a que

(...) no son simples listados de textos a ser consultados en una unidad documental (biblioteca, archivo, hemeroteca, etc.), sino que es necesario implementar toda una técnica investigativa que consiste en organizar, seleccionar y relacionar, a través de un riguroso trabajo, la información que se encuentra en ellos (Botero, 2003, p. 113).

En cuanto a la metodología se hizo uso de fuentes secundarias, como lo son la ley 1564/2012 y la jurisprudencia de las altas cortes, en especial de la Corte Constitucional en sus pronunciamientos sobre la materia y de la Corte Suprema de Justicia, las cuales se examinaron mediante fichas de análisis jurisprudencial (Yáñez, 2014), textos y artículos de revistas científicas nacionales y extranjeras.

Para la recolección de la información se manejaron fichas bibliográficas que permitieron su sistematización, de tal modo que se posibilitó la definición de categorías y variables de análisis, que posteriormente se usaron para el análisis de la información. En efecto, para la recopilación de la información se consultaron las bibliotecas de las universidades con sede en Manizales, Pereira y San José de Cúcuta y bases de datos jurídicas.

\section{Esquema de resolución del trabajo}

El artículo se divide en cuatro partes. La primera describe el problema jurídico que puede estar presentándose en los procesos de única instancia contemplados en el CGP frente a la posible vulneración de las garantías constitucionales del debido proceso y la doble instancia. La segunda establece si dichos procesos de única instancia se enmarcan en los instrumentos internacionales que protegen estos derechos y que ingresan al ordenamiento jurídico a través de la figura del bloque de constitucionalidad. La tercera hace un juicio integrado de constitucionalidad para ponderar los principios de celeridad y de la doble instancia. Finalmente, se expone las conclusiones de esta indagación.

\section{La garantía procesal y constitucional del debido proceso y la doble instancia en la figura de la única instancia: reser- va legislativa vs. aplicación directa de los derechos fundamentales}

El artículo 31 de la Constitución Política de 1991 estableció el principio de la doble instancia como una garantía procesal (Devis, 1999; López, 1997) en la que "toda sentencia judicial podrá ser apelada o consultada, salvo las excepciones que consagre la ley".

En coherencia con este artículo, se advierte la configuración de una regla general y de una excepción: como regla general se observa que contra todas las sentencias proferidas por los jueces y magistrados del país, es procedente el recurso de apelación en aras de garantizar la materialización del principio de la doble instancia; como excepción, el legislador colombiano tiene la reserva legal de implantar en determinados procesos la única instancia.

El CGP en sus artículos 17, 19 y 21 fijó la competencia de los jueces civiles municipales, jueces civiles de circuito y jueces de familia en procesos de única instancia, disposiciones que pueden constituirse en una infracción a la garantía procesal y constitucional del debido proceso y la doble instancia (Jaramillo, 2012).

Así las cosas, el artículo 17 del CGP consagró la competencia de los jueces civiles municipales en única instancia para conocer de los procesos contenciosos de mínima cuantía; de los procesos de sucesión de mínima cuantía; de la 
celebración del matrimonio civil; y de los conflictos en materia comercial contemplados en los artículos 913, 914, 916, 918, 931, 940, 1231, 1469 y 2026 del Código de Comercio. De los asuntos correspondientes al juez de familia en única instancia cuando no se encuentre juez de familia o promiscuo de familia en el respectivo municipio; de las controversias surgidas en los procedimientos de insolvencia de personas naturales no comerciantes y de su liquidación patrimonial; entre otros procesos.

El artículo 19 del mismo código fija la competencia de los jueces civiles del circuito en única instancia para conocer de los procesos relacionados con la propiedad intelectual; de los trámites de insolvencia no atribuidos a la Superintendencia de Sociedades y de los procesos de insolvencia de personas naturales comerciantes; y del nombramiento de árbitros, cuando no se presentó común acuerdo por los interesados.

Por último, el artículo 21 establece que los jueces de familia conocen en única instancia de la protección del nombre de personas naturales; de la suspensión y restablecimiento de la vida en común de los cónyuges y la separación de cuerpos y de bienes por mutuo acuerdo; de la custodia, cuidado personal y visitas de los niños, niñas y adolescentes; de la citación judicial para el reconocimiento de hijo extramatrimonial, prevista en la ley; de los permisos a menores de edad para salir del país; de la fijación, aumento, disminución y exoneración de alimentos; de las medidas de protección de la infancia en los casos de violencia intrafamiliar, cuando en el lugar no exista comisario de familia; entre otros asuntos que se consignan en la mencionada disposición.

Esta normativa puede estar vulnerando el principio del debido proceso consagrado en el artículo 29 de la Constitución Política de 1991, pues se evidencia un obstáculo en sede judicial que se relaciona con la materialización efectiva de las garantías procesales de acceder a una doble instancia en todos los procesos (Taruffo, 2007) independiente de su cuantía o relevancia jurídica subjetivamente otorgada por el legislador. $\mathrm{Al}$ respecto la Corte Constitucional ha motivado lo siguiente:

El artículo 29 constitucional prevé el derecho del debido proceso, como una serie de garantías que tienen por fin sujetar las actuaciones de las autoridades judiciales y administrativas a reglas específicas de orden sustantivo y procedimental, con el fin de proteger los derechos e intereses de las personas en ellas involucrados. (...) De ahí que esta Corporación haya definido el derecho fundamental del debido proceso, como la regulación jurídica que de manera previa limita los poderes del Estado y establece las garantías de protección a los derechos de los individuos, de modo que ninguna de las actuaciones de las autoridades públicas dependa de su propio arbitrio, sino que se encuentren sujetas a los procedimientos señalados en la ley (sentencia C-154/2004).

Ahora bien, no obstante las garantías contempladas en el debido proceso (Devis, 1999), se observa que el legislador colombiano tiene dos prohibiciones constitucionales de eliminar la doble instancia: la primera cuando se profieren sentencias condenatorias en materia penal; en consecuencia, el inciso cuarto del artículo 29 de la Carta dicta expresamente que el condenado tiene derecho a impugnar la sentencia condenatoria ${ }^{2}$. La segunda se identifica en el inciso segundo del artículo 86, el cual consagra la impugnación de los fallos proferidos por la rama judicial en los eventos de protección de los derechos fundamentales mediante la presentación de una acción de tutela.

En este orden de ideas, la Corte Constitucional de Colombia en sentencia C-900/2003 conoció

\footnotetext{
2 Constitución Política de 1991, artículo 29, inciso cuarto: "Toda persona se presume inocente mientras no se la haya declarado judicialmente culpable. Quien sea sindicado tiene derecho a la defensa y a la asistencia de un abogado escogido por él, o de oficio, durante la investigación y el juzgamiento; a un debido proceso público sin dilaciones injustificadas; a presentar pruebas y a controvertir las que se alleguen en su contra; a impugnar la sentencia condenatoria, y a no ser juzgado dos veces por el mismo hecho".
} 
de la acción de inconstitucionalidad presentada contra el artículo 48 de la ley 794/2003, en la que el actor argumentaba que esta disposición debía declararse inexequible porque desconocía el derecho a la igualdad y el principio de la doble instancia al eliminar el recurso de apelación contra el mandamiento de pago. La alta corte sostuvo que esta eliminación del recurso no constituía una vulneración al principio de la doble instancia y del debido proceso, pues el constituyente de 1991 confirió facultades al legislador para establecer excepciones a la doble instancia y, por ende, instaurar procesos de única instancia. La honorable corporación indicó:

La Corte estima que tal violación no acontece, teniendo en cuenta que el Constituyente autorizó al legislador para establecer excepciones a dicho principio. En consecuencia, el cumplimiento de ese mandato no comporta violación alguna de la Constitución. Solo cuando se elimine la segunda instancia contra las providencias condenatorias, los fallos de tutela o de manera irrazonable se suprima la apelación de providencias judiciales es dable afirmar que se vulnera el principio de la doble instancia.

En el presente caso tal circunstancia no tiene lugar, en primer lugar, porque no se trata de una sentencia condenatoria ni de tutela y, en segundo lugar, porque de acuerdo con lo expuesto en los puntos anteriores, no se avizora ninguna actuación desproporcionada e irrazonable del Legislador, que permita inferir el quebrantamiento de normas, principios o valores constitucionales. En ese sentido, contrariamente a lo afirmado por el actor, el ejecutado cuenta con otros medios de defensa igual o mayormente eficaces que el recurso de apelación contra el mandamiento de pago, como son las excepciones perentorias (sentencia C-900/2003).

Atendiendo los argumentos precedentes, la Corte Constitucional en sentencia C-345/1993 sostiene que el principio de la doble instancia no forma parte integral del núcleo esencial del debido proceso ${ }^{3}$, pues el legislador puede fijar las excepciones a dicho principio a través de la asignación de la única instancia. Al respecto, la alta corte señala:

La doble instancia no pertenece al núcleo esencial del debido proceso - pues la ley puede consagrar excepciones-, salvo cuando se trata de sentencias condenatorias, las cuales siempre podrán ser impugnadas. La doble instancia es apenas un mecanismo instrumental de irrigación de justicia y de incremento de la probabilidad de acierto en la función estatal de dispensar justicia al dirimir los conflictos (dada por la correlación entre verdad real y decisión judicial $)^{4}$. Su implementación solo se impone en aquellos casos en que tal propósito no se logre con otros instrumentos (sentencia C-345/1993).

Así mismo, la alta corte manifestó que el debido proceso no debe regularse de idéntica forma en todos los procesos judiciales, pues con ello se estaría desconociendo el poder de configuración normativa que ejercen los congresistas como representantes del pueblo y como órgano democrático por excelencia en el Estado colombiano. Sobre el tema, puede verse:

La sola consagración del debido proceso como derecho fundamental, no puede derivarse, en manera alguna, una idéntica regulación de sus distintos contenidos para los procesos que se adelantan en las distintas materias jurídicas pues, en todo aquello que no haya sido expresamente previsto por la Carta, debe advertirse un espacio apto para el ejercicio del poder de configuración normativa que el pueblo

3 Sobre la expresión "núcleo esencial", si bien pueden formularse objeciones y serias críticas con relación a cuál es su verdadero contenido y límites -lo cual no es el propósito de esta investigación-, se parte de una realidad: la jurisprudencia de la Corte Constitucional creó el concepto y este ha sido objeto de interpretación y aplicación.

4 En cuanto al fin del proceso desde la búsqueda de la verdad o la solución del conflicto consúltese Sánchez (2013). 
ejerce a través de sus representantes. La distinta regulación del debido proceso a que pueda haber lugar en las diferentes materias jurídicas, siempre que se respeten los valores superiores, los principios constitucionales y los derechos fundamentales, no es más que el fruto de un proceso deliberativo en el que, si bien se promueve el consenso, también hay lugar para el disenso pues ello es así ante la conciencia que se tiene de que, de cerrarse las puertas a la diferencia, se desvirtuarían los fundamentos de legitimidad de una democracia constitucional (sentencia C-131/2002).

No obstante este panorama jurídico relacionado con la reserva material que permite al legislador elaborar excepciones en la aplicación de la doble instancia, es importante recordar que el ordenamiento jurídico colombiano, desde la expedición de la Constitución Política de 1991 se estructura a partir de un sistema de fuentes en donde el bloque de constitucionalidad $-\mathrm{y}$ por ende, la Carta de derechos-, es la norma jurídica que orienta la creación y la validez de las demás disposiciones, evidenciándose que ninguna decisión judicial, y mucho menos una política pública de descongestión judicial, puede desatender los derechos fundamentales durante el desarrollo de un proceso (Ramírez, 2003; Rojas, 2011).

Así las cosas, está la imperiosa tarea por parte de todos los operadores jurídicos del país de realizar una correcta hermenéutica jurídica sobre las disposiciones del bloque de constitucionalidad como la Carta de Derechos de 1991, los tratados internacionales y convenciones sobre derechos humanos, jurisprudencia constitucional, etc. (Yáñez y Yáñez, 2012), frente a la normativa legal del año 2012 referente a la regulación de los procesos de única instancia. De lo contrario, al no efectuarse un adecuado esquema de lectura garantista constitucional, se puede afirmar que la rama legislativa colombiana en su intento por descongestionar los despachos estará vulnerando derechos fundamentales estructurales del Estado social de derecho, que en últimas alejan a la función judicial de su valor más elevado: la justicia (Rodríguez, 2011).

Se trae a colación un apartado contenido en el salvamento parcial de voto a la sentencia C-131/2002 elaborada por el magistrado Rodrigo Escobar Gil, en la que se plasma que la configuración normativa como ejercicio de la voluntad popular y democrática del Estado de derecho no puede ser ilimitada:

La potestad de configuración normativa de los derechos fundamentales varía en la regulación de los distintos procesos, en razón a los variados bienes jurídicos objeto de protección y a las finalidades perseguidas en cada caso. No obstante, la potestad de configuración normativa como ejercicio de la voluntad popular y democrática del Estado de Derecho, no puede ser concebida como una atribución ilimitada y absoluta que conduzca a la arbitrariedad y al desconocimiento de los fines, principios y valores que emanan de la Constitución, y del núcleo esencial de los derechos fundamentales de los individuos. De esta manera, la Corte ha establecido que cuando entren en conflicto el interés general en el logro de una justicia apremiante y eficaz, $y$, los derechos fundamentales como el debido proceso y la defensa técnica, deben primar estos últimos en cuanto al mantenimiento y protección de su contenido esencial.

Este argumento permite comprender que los derechos fundamentales constitucionales se constituyen como limitantes al principio de mayorías dentro de una forma de gobierno democrática (Barragán, 2003). En consecuencia, en el evento de colisión entre dos derechos o principios constitucionales, es menester aplicar la ponderación para otorgarle un mayor peso a uno de los principios. Así, en el salvamento parcial que presentó el magistrado Escobar Gil se observa que en la colisión entre el interés general en el logro de una justicia apremiante $y$ eficaz $y$, los derechos fundamentales como el debido proceso, debe primar este último como 
protección de los derechos individuales de los asociados (Palacios, 2012; Pérez, 2010).

Al respecto, se reitera por este magistrado una sentencia de la Corte Constitucional que hace referencia a la prevalencia del derecho fundamental al debido proceso sobre la eficacia de la administración de justicia en Colombia. Se cita in extenso por lo valioso del contenido para el desarrollo del presente artículo:

Esta Corporación no duda en señalar que en caso de que no pueda establecerse una armonización concreta de los principios constitucionales en conflicto, debe darse preferencia al derecho fundamental al debido proceso, pues la eficacia de la administración de justicia y la seguridad jurídica no pueden alcanzarse a riesgo de sacrificar los derechos fundamentales de las personas. La justicia está al servicio de esos derechos, por lo cual en estos casos no puede aplicarse mecánicamente el principio constitucional de prevalencia del interés general (CP art. $\left.1^{\circ}\right)$ sobre el particular, pues en tales eventos la norma constitucional relevante es aquella que dispone que el Estado reconoce la primacía de los derechos inalienables de la persona (CP art. 5\%). Por ello, en caso de conflicto irresoluble entre derechos constitucionales tan fundamentales, como la vida, la libertad o el debido proceso, y la persecución de objetivos estatales de interés general, como los que se logran con una justicia más eficaz, en principio debe el juez constitucional dar prevalencia a los derechos de la persona, pues es la única forma de conferir un efecto interpretativo real a la Carta de derechos. Este criterio hermenéutico es necesario, pues no puede darse preferencia a los intereses de la mayoría y al bienestar colectivo siempre que entran en conflicto con un derecho constitucional de una persona, con el deleznable argumento de que el derecho individual es particular, y el interés general prima siempre sobre el particular.
En efecto, conviene recordar que los derechos constitucionales son precisamente limitaciones al principio de mayoría y a las políticas destinadas a satisfacer el bienestar colectivo. Esto significa que, como lo reconoce la doctrina, los derechos fundamentales son verdaderas cartas de triunfo contra el bienestar colectivo pues "condicionar la validez de un derecho constitucional a los criterios de las mayorías es quitarle toda su eficacia específica puesto que, en una gran medida, los derechos constitucionales fundamentales son las promesas que formulan las mayorías a las minorías - y a esas minorías radicales que son las personas - de que su dignidad e igualdad serán siempre respetadas". Por ello debe entenderse que el respeto de esos derechos es un componente integrante del interés general, tal y como esta Corporación lo había señalado (sentencia T-669/1996, énfasis dentro del texto).

De conformidad con lo explicado hasta aquí, se resalta que la reserva que tiene el legislador para restringir los derechos al debido proceso y a la doble instancia en determinados procesos es contraria a la Constitución Política de 1991, debido a que el artículo 29 superior señala expresamente que el debido proceso se aplicará a toda actuación judicial y administrativa y, por ende, el principio de la doble instancia como parte del núcleo esencial de esta garantía procesal, debe ser también respetado.

En este orden de ideas, el principio de mayoría dentro de la democracia colombiana no es absoluto, por tanto, la configuración normativa que el pueblo delega en la rama legislativa no puede establecer procesos de única instancia para el conocimiento de determinados temas; pues esto estaría vulnerando los derechos fundamentales de las personas que consideren apelar la sentencia desfavorable (Marinoni, 2007; Morales, 2010; Ovalle, 2007). Sobre el particular, Miguel Rojas (2011) argumenta que

(...) la situación de la justicia en Colombia muestra un inocultable estado de cosas 
inconstitucional. La tutela judicial efectiva, el respeto del debido proceso y la garantía de un proceso de duración razonable y sin dilaciones injustificadas contempladas en los instrumentos internacionales de derechos humanos que integran el bloque de constitucionalidad (CP, art. 93) no han pasado de ser un discurso estéril ${ }^{5}$ (p. 112).

\section{Juicio integrado de constitucionalidad: principio de celeridad vs. principio de la doble instancia}

En el contexto de un Estado social de derecho, inmerso en la teoría del derecho del neoconstitucionalismo, no es admisible que un proceso judicial se lleve a cabo desconociendo los derechos fundamentales del debido proceso y de la doble instancia que establece la Constitución Política de 1991 que es "normas de normas" $y$, por tanto, implica que cualquier norma jurídica (sentencia judicial) debe ser expedida de conformidad con su contenido (Zagrebelsky, 1995). Para Ramírez:

(...) haciendo la relación entre Estado democrático y derechos fundamentales, que para que no se degenere el Estado en un derecho formal e "injusto", el Estado de derecho no solo debe garantizar formas $y$ procedimientos de actuación estatal, sino que también debe proponer objetivos concretos y metas, basándose en la protección y el respeto de la dignidad humana, las libertades fundamentales y los derechos ciudadanos, que el poder estatal tiene que observar como derecho directamente aplicable (2003, p. 118).

En este sentido, en la normativa internacional se registra el artículo 8 de la Convención Americana sobre Derechos Humanos (Pacto de San José de Costa Rica, 1969) y el artículo 14 del Pacto Internacional de Derechos Civiles y Políticos (1966), los cuales incluyen el principio de la

Sobre el estado de cosas inconstitucional consúltese Calderón (2014). doble instancia como parte del debido proceso. El Estado de Colombia suscribió ambos tratados y está en la obligación de cumplirlos en virtud del principio del derecho internacional pacta sunt servanda.

Así pues, en Colombia a partir de la expedición de la Constitución de 1991 se hizo posible integrar el derecho internacional con el derecho interno, sin encontrarse obstáculos políticos como el concepto de la soberanía nacional, ni jurídicos, como el concepto de la supremacía de la Carta Magna (Bernal, 2011). Es de anotar, que el derecho sufrió fuertes transformaciones después de la Segunda Guerra Mundial, coyuntura en la cual la comunidad internacional comprendió que las Constituciones no podían seguir siendo simples acuerdos políticos para establecer la estructura del Estado, sino un catálogo de derechos fundamentales que debía respetarse en cualquier circunstancia.

El continente americano no podía rezagarse de esta transformación del derecho. Por ello la Corte Interamericana de Derechos Humanos introdujo el concepto de "control de convencionalidad" que consiste en el estudio realizado por todos los jueces y magistrados del sistema interamericano, orientado a constatar que una norma jurídica de un Estado se ajuste a los principios y obligaciones de la Convención Americana sobre Derechos Humanos. Al respecto, esta Corte ordena a la rama judicial aplicar el control de convencionalidad:

Los jueces y órganos vinculados a la administración de justicia en todos los niveles están en la obligación de ejercer ex officio un "control de convencionalidad" entre las normas internas y la Convención, en el marco de sus respectivas competencias y de las regulaciones procesales correspondientes (Caso Almonacid Arellano y otros vs. Chile, 2006).

6 Sobre la recepción del control de convencionalidad en Colombia a partir de la jurisprudencia del Consejo de Estado consúltese Sánchez (2015). 
Como se evidencia, el control de convencionalidad tiene entre sus fines el de armonizar el derecho interno con la Convención Americana sobre Derechos Humanos y los demás instrumentos de protección de los derechos humanos. Sobre el tema Quinche manifiesta:

El control de convencionalidad es propiamente una actividad judicial, de competencia de la Corte Interamericana de Derechos Humanos y de todos los jueces locales de los distintos Estados parte de la Convención Americana, encaminada a la protección y efectividad de los derechos humanos en la región. Dicho control se ejerce tanto sobre las leyes y los enunciados normativos que se profieren en los distintos Estados parte, como sobre los hechos violatorios de los derechos humanos que en ellos acontecen (2014, p. 50).

Además de este estricto estudio jurídico, es menester mencionar tres aspectos. El primero se asocia con las razones objetivas que pudo tener presente el legislador colombiano para dotar de mayor importancia algunos litigios sobre otros, asignando una única instancia para algunos asuntos y una doble instancia para la mayoría de los asuntos de conocimiento por parte de la jurisdicción ordinaria.

El segundo alude al ámbito del litigante, en el cual pueden existir procesos jurídicos trascendentes, sin importar su valor o cuantía. Tal cuestión depende de muchas variables, la psicología del litigante, el interés subjetivo por lo debatido, etc. El tercer aspecto consiste en si el procedimiento de la única instancia cumple la garantía de la heterocomposición: existencia de un tercero imparcial, resolución adecuada de los conflictos; sobre el tema, Azula menciona que "la heterocomposición implica la intervención de un tercero, ajeno a los sujetos, entre quienes se suscita el conflicto, función que se atribuye al Estado y realiza por conducto de la rama judicial mediante la sentencia, previo el respectivo proceso" (2008, p. 114).
Ahora bien, como se explicó en el acápite anterior, el principio de mayoría dentro de la democracia no es absoluto, por tanto, la configuración normativa que realiza el Congreso de la República para fijar procesos de única instancia no puede desconocer derechos fundamentales que protegen instrumentos internacionales, los cuales se introducen en el ordenamiento jurídico colombiano mediante la figura del bloque de constitucionalidad (Uprimny, 2005) y que son de inmediata aplicación, máxime que gozan de un control de convencionalidad por parte de cualquier juez y magistrado; de lo contrario, esta configuración normativa ilimitada vulneraría los derechos fundamentales de las personas que consideren apelar la sentencia desfavorable.

Como se puede apreciar, hay una tensión entre Constitución y democracia, siendo la primera un límite a la capacidad decisional del pueblo frente a los derechos fundamentales dentro de la democracia (Arango, 2004). En este sentido, la Corte Constitucional precisa

(...) que si bien el legislador en ejercicio de su facultad constitucional de hacer las leyes y expedir códigos en las distintas ramas del Derecho a que alude el artículo 150 superior, cuenta con una amplia potestad de configuración, dicha potestad no es absoluta pues ella encuentra sus límites en los principios y valores consagrados en el ordenamiento constitucional, que en materia de procedimientos particularmente imponen el respeto de los derechos de acceso a la administración de justicia, debido proceso e igualdad (sentencia C-718/2012).

En cuanto a los motivos que tuvo el legislador para establecer la figura de la única instancia, esta se justificó como un mecanismo para descongestionar la justicia. Así pues, el legislador colombiano en el marco de su poder de libre configuración determinó la única instancia restringiendo los principios del debido proceso y de la doble instancia; decisión que puede aparecer como la más gravosa para los derechos procesales y constitucionales de los litigantes 
(demandante y demandado), principalmente si se pueden adoptar otras medidas para cumplir con el objetivo constitucional de contar con una administración de justicia efectiva, tales como la mayor inversión en despachos judiciales, la capacitación judicial o la evaluación de los resultados de las últimas reformas procesales enfocadas en la oralidad. Conforme con el argumento precedente, en términos de un sector de la doctrina:

(...) de aquí que el acceso a la administración de justicia implica, entonces, la posibilidad de que cualquier persona solicite a los jueces competentes la protección o el restablecimiento de los derechos que consagran la Constitución y la Ley. Sin embargo, la función en comento no se entiende concluida con la simple solicitud o el planteamiento de las pretensiones procesales ante las respectivas instancias judiciales; por el contrario, el acceso a la administración de justicia debe ser efectivo, lo cual se logra cuando, dentro de determinadas circunstancias y con arreglo a la ley, el juez garantiza una igualdad a las partes, analiza las pruebas, llega a un libre convencimiento, aplica las garantías contempladas en la Constitución y la ley (Palacios, 2012, p. 14).

Sobre las medidas para descongestionar la justicia, se recuerda que entre los años 2011 y 2012 , el Estado colombiano hizo una de sus más grandes apuestas en relación con la rama judicial del poder público, la cual fue una muestra importante de su interés por descongestionar los despachos judiciales e imprimirle celeridad a la administración de justicia. Esta apuesta se plasmó en el frustrado y polémico proyecto titulado: "Por medio del cual se reforman artículos de la Constitución Política con relación a la administración de justicia y se dictan otras disposiciones", conocido mediáticamente como la "reforma a la justicia".

En dicho proyecto de acto legislativo se pretendió, entre otras cosas, entregar funciones judiciales a los abogados, centros de arbitraje y conciliación, notarios y a algunas de las autoridades admi- nistrativas, es decir, una variación procesal por competencias con un espectro amplio.

Se resalta entonces la intención de asignar funciones jurisdiccionales propiamente dichas a los notarios, argumentando "que indudablemente, ayudará a descongestionar los despachos judiciales y a generar más acceso eficaz a la justicia" (Congreso de la República de Colombia, 2011). En este sentido, tratando de explicar mejor la situación, la exposición de motivos pone como ejemplo el proceso de pertenencia sobre bienes destinados a vivienda de interés social (tal y como lo establecían los artículos 10-14 de la ley 1183/2008, declarados inexequibles en sentencia C-1159/2008) (Congreso de la República de Colombia, 2011), también menciona los procesos de jurisdicción voluntaria, ciertos temas del derecho de familia, e incluso, los procesos ejecutivos.

Como es de público conocimiento, el citado acto legislativo 07/2011 lo archivó el Congreso el día 28 de junio de 2012, luego de un intenso debate donde se dio trámite a las objeciones incoadas por el presidente de la República Juan Manuel Santos sobre ese proyecto. Del archivo del proyecto de reforma constitucional, pese a haber cercenado la posibilidad de encontrar notarios con competencias jurisdiccionales en virtud de mandato constitucional, se puede aseverar la suma importancia que tiene para el Gobierno la entrega de labores jurisdiccionales a otras ramas del poder público diferentes a la que tradicionalmente ejerce esa labor, pues con ello se contribuye a descongestionar el atiborrado aparato judicial colombiano.

Por todos los argumentos precedentes, si bien la reforma a la justicia de la República de Colombia desde una perspectiva amplia, es difícil de conseguir, sí se puede insistir en hacer la reforma desde una perspectiva estricta que permita la protección del principio de la doble instancia y de la garantía del debido proceso.

De esta manera, para solucionar el problema de investigación planteado, a continuación se desa- 
rrolla un "juicio integrado de constitucionalidad" para determinar si la figura de la única instancia, definida en el CGP, constituye una infracción a la garantía procesal y constitucional del debido proceso y la doble instancia.

Antes de pasar al ejercicio, se señala que la evolución de la Corte Constitucional de Colombia ha sido creciente y dirigida a la aplicación de la razonabilidad entorno a la igualdad y la proporcionalidad de principios y derechos fundamentales en colisión; en consecuencia se distinguen al menos tres etapas jurisprudenciales:

1. Etapa de ingreso (1992-1993): uso de la ponderación como evaluación comparativa concreta sin estructura metodológica clara.

2. Etapa de posicionamiento (1994-2001): se desarrolló un debate de posicionamiento de la ponderación dentro del razonamiento judicial nacional, especialmente orientado en el control abstracto de las leyes y la facultad discrecional del Congreso de la República para su configuración, se definieron diferentes tendencias donde se atenuaba dicha intensidad de intervención. El avance logrado expande el alcance del derecho constitucional por intermedio del progreso de la argumentación jurídica.

3. Etapa de consolidación (desde el 2002): se establece la ponderación como principal modo de argumentación para dirimir controversias sobre el alcance, límite y colisión de derechos constitucionales, se fija una metodología que delimita los criterios de implementación, estructura, los grados de intensidad y su conveniencia para aplicarse por parte de los jueces ordinarios.

En desarrollo de tan vasta labor interpretativa y pedagógica judicial, la alta corte configuró una metodología propia para la evaluación de asuntos constitucionales, integrando el test de igualdad de estirpe norteamericana y el juicio de proporcionalidad establecido en Europa, aprovechando las ventajas de los dos métodos para minimizar las polémicas suscitadas entorno a sus decisiones.

Deviene de todo lo anterior el llamado por la honorable corporación "juicio integrado de constitucionalidad", donde se somete a un análisis minucioso asuntos de interés fundamental en la actualidad jurídica, que puede representar colisión de principios y derechos de rango supremo y donde el núcleo esencial del estudio es el principio de proporcionalidad, mayormente decantado en la doctrina alemana, al respecto el profesor Alexy explica:

En el primer paso es preciso definir el grado de la no satisfacción o de afectación de uno de los principios. Luego, en un segundo paso, se define la importancia de la satisfacción del principio que juega en sentido contrario. Finalmente, en un tercer paso, debe definirse si la importancia de la satisfacción del principio contrario justifica la restricción o la no satisfacción del otro (1997, p. 16).

Cabe reiterar el concepto del principio de proporcionalidad contenido en la sentencia C-022/1996:

El concepto de proporcionalidad comprende tres conceptos parciales: la adecuación de los medios escogidos para la consecución del fin perseguido, la necesidad de la utilización de esos medios para el logro del fin (esto es, que no exista otro medio que pueda conducir al fin y que sacrifique en menor medida los principios constitucionales afectados por el uso de esos medios), y la proporcionalidad en sentido estricto entre medios y fin, es decir, que el principio satisfecho por el logro de este fin no sacrifique principios constitucionalmente más importantes.

Donde la (1) adecuación de medios, (2) la necesidad y (3) la proporcionalidad (ponderación) se vislumbran como esenciales elementos del consiguiente ejercicio. 
Para efectos de orden y claridad, la tabla 1 muestra la síntesis de las principales variables para el desarrollo de este juicio integrado de constitucionalidad, a partir de la cual se hará un ejercicio de análisis donde se intentará interpretar los principios que orientan la aplicación del test de proporcionalidad ${ }^{7}$ frente al problema jurídico planteado.

Tabla 1. Test de proporcionalidad para el control abstracto de constitucionalidad

\begin{tabular}{ll}
\hline \multicolumn{1}{c}{ Variable } & \multicolumn{1}{c}{ Valor } \\
\hline Caso & $\begin{array}{l}\text { Vulneración del principio de la doble } \\
\text { instancia en los procesos de única } \\
\text { instancia establecidos en el Código } \\
\text { General del Proceso } \\
\text { Única instancia para descongestión } \\
\text { judicial }\end{array}$ \\
Medio 2 & $\begin{array}{l}\text { Doble instancia para garantías pro- } \\
\text { cesales }\end{array}$ \\
Fin & Derecho al debido proceso \\
$\begin{array}{l}\text { Derecho } \\
\text { fundamental }\end{array}$ & $\begin{array}{l}\text { Principio de celeridad us. principio de } \\
\text { la doble instancia }\end{array}$ \\
\hline
\end{tabular}

Fuente: elaboración propia.

\section{Derechos en contienda}

Se propone fundamentalmente la violatoria de tres enunciados constitucionales:

Las disposiciones 17, 19 y 21 de la ley 1564/2012 primordialmente proponen contienda con los artículos 12, 29 y 31 de la Constitución Política de 1991, título II, de los derechos, las garantías y los deberes: igualdad, debido proceso y doble instancia ${ }^{8}$.

$7 \quad$ En este test de proporcionalidad no se considera a la acción de tutela como variable dada su excepcionalidad a partir del principio de subsidiariedad o definitividad. En este sentido, la suficiencia de la acción de tutela es irrelevante por cuanto el objeto de investigación se delimita en lo que puede denominarse curso ordinario de un proceso civil o del ámbito de aplicación del CGP.

8 En este punto debe indicarse que la problemática de la inmediación y la intensidad dada a este principio desde el CGP resulta impertinente en el test que se realiza, por cuanto el objeto de investigación se concentra sobre
Paso uno: adecuación de medios

En este punto se establece la relación medio-fin, se analiza el uso del medio puesto en controversia y su legitimidad y eficiencia frente al fin buscado. Así, el medio 1 vulnera el acceso a la justicia y demás garantías procesales al fijar la figura de la única instancia. Por otro lado, el medio legítimo propone la garantía procesal de la doble instancia con el propósito de tutelar el debido proceso.

\section{Paso dos: necesidad}

Aquí se analiza si existen otros medios legítimos menos lesivos para la satisfacción del derecho, se trata de una relación medio-medio; el objetivo es verificar si hay otros u otro medio que intervengan el mismo principio/derecho fundamental, su grado de intensidad o afectación al derecho a fin de determinar su menor lesividad, y por tanto, su elección preferente.

Se propone el medio 2 como el menos lesivo para la realización del fin, ya que la creación de procesos de única instancia no puede constituirse en la solución genérica para la congestión judicial del país, además no puede admitirse en un Estado social de derecho -inmerso en un ordenamiento jurídico principialístico- una configuración legislativa absoluta, o libre de restricciones representadas en el respeto a las garantías fundamentales del Estado constitucional, dentro de las cuales son determinantes las prerrogativas procesales. Si bien el legislador puede elegir múltiples medios para garantizar el acceso y celeridad a la justicia, no puede adoptar medios que sacrifiquen o limiten en exceso los derechos señalados.

\section{Paso tres: ponderación}

La proporcionalidad en sentido estricto tiene diferentes intensidades, versa sobre una comparación entre el grado de realización u opti-

esa posibilidad real de que otro juez diga el derecho respecto a la decisión de su inferior, no respecto al papel del juez de primera instancia y su actividad, por ejemplo, en el decreto y práctica de pruebas al punto en que no se hace necesario que se habilite la revisión por su superior a partir de la apelación. 
mización del fin constitucional y la intensidad de la intervención en el derecho fundamental. Así las cosas, para la realización del debido proceso se muestra más efectiva la protección del derecho fundamental a la doble instancia para no afectar la esencia antropocéntrica ni la supremacía de la Constitución Política de 1991 $y$, por ende, la coherencia entre la normativa internacional y la normativa interna. En este sentido, se encuentra que el legislador no aplicó cada uno de los parámetros instaurados por la Corte Constitucional en sentencia C-103/2005 para fijar excepciones al principio de la doble instancia. $\mathrm{Al}$ respecto se mencionan:

(i) La exclusión de la doble instancia debe ser excepcional; (ii) Deben existir otros recursos, acciones u oportunidades procesales que garanticen adecuadamente el derecho de defensa y el derecho de acceso a la administración de justicia de quienes se ven afectados por lo actuado o por lo decidido en procesos de única instancia; (iii) La exclusión de la doble instancia debe propender por el logro de una finalidad constitucionalmente legítima; (iv) La exclusión no puede dar lugar a discriminación.

De este modo, en ningún evento, la decisión o la potestad legislativa de establecer un proceso de única instancia puede ser ilimitada, o estar exenta de justificaciones y verificaciones frente a la armonización concreta que debe existir respecto a los derechos fundamentales procesales, lo contrario supondría desvirtuar la regla indicada; en palabras de la alta corte, se respalda esta afirmación:

El principio general establecido por el artículo 31 Superior es que todos los procesos judiciales son de doble instancia y que por consiguiente, como los procesos de única instancia son una excepción a ese principio constitucional, debe existir algún elemento que justifique esa limitación, pues otra interpretación conduciría a convertir la regla (doble instancia) en excepción (única instancia); en tanto la posibilidad de apelar tiene vínculos estrechos con el derecho de defensa y la Constitución y los tratados de derechos humanos garantizan a toda persona el derecho al debido proceso -que tiene como componente esencial el derecho de defensa-. La Carta establece el principio de igualdad (CP art. 13), que obviamente se proyecta sobre la regulación de los procesos y recursos. Por ende, aunque el Legislador cuenta con una amplia facultad discrecional para instituir las formas con base en las cuales se ventilarán las diferentes controversias jurídicas que surjan entre las personas, de acuerdo con el artículo 150, numerales 1 o. y 2o., de la Constitución, es obvio que las excepciones a la doble instancia no pueden ser discriminatorias (sentencia C-103/2005).

En síntesis, pese al trabajo jurisprudencial adelantado por la Corte Constitucional para decantar los cuatro parámetros para fijar excepciones al principio de la doble instancia por parte de la rama legislativa, se observa que el principio de la doble instancia fortalece la esencia del fin propuesto: el debido proceso; por ende, este principio constitucional y garantía procesal que permite a las personas el acceso a la justicia para controvertir la decisión tomada en una sentencia, toma un peso mayor que el principio de la celeridad, al que le interesa más la forma que el fondo de las actuaciones judiciales.

En tal sentido, la garantía del debido proceso asegura el acceso a la justicia de una manera integral. Por esto se afirma que el legislador mediante el establecimiento de la figura de la única instancia terminó restringiendo indebidamente los derechos y garantías procesales.

\section{Conclusiones}

Los procesos de única instancia establecidos en los artículos 17, 19 y 21 de la ley 1564/2012 o CGP, se redactaron a partir de la reserva material que permite al legislador elaborar excepciones en la aplicación de la doble instancia; no obstante, como se demostró en esta investigación, nuestro ordenamiento jurídico, desde la entrada 
en vigencia de la Constitución Política de 1991, se fundamenta en la aplicación de principios como garantía de una Carta de derechos en la que las leyes - para encontrar su validez material- deben adecuarse a los contenidos constitucionales, evidenciándose que ninguna providencia judicial, por sencilla -caso fácil- que sea su resolución, debe dejar de ser revisada en una segunda instancia.

El argumento anterior se fundamentó en la existencia de la Convención Americana sobre Derechos Humanos y del Pacto Internacional de Derechos Civiles y Políticos, los cuales regulan el principio de la doble instancia como parte del debido proceso y forman parte integral del ordenamiento jurídico colombiano a través del bloque de constitucionalidad. Por esta razón, la configuración normativa del legislador no puede ser absoluta, permitiéndole limitar una garantía procesal de rango constitucional mediante la fijación de procesos de única instancia como los establecidos en la ley 1564/2012; decisión que se torna inconstitucional debido a que el principio de celeridad orientado a descongestionar los despachos judiciales no puede tener, en un Estado social de derecho, un mayor peso que el principio de la doble instancia que forma parte esencial de la garantía procesal del debido proceso.

Es menester entonces que en todo proceso, las partes intervinientes cuenten -cuando se ven afectadas por lo decidido en primera instanciacon los recursos, acciones u oportunidades procesales que les garantice adecuadamente la materialización de sus derechos fundamentales, tal como se define de modo expreso en el artículo 89 constitucional para la protección judicial de los derechos.

En la actualidad no se ha promovido demanda de inconstitucionalidad ante la Corte Constitucional contra las disposiciones que definen los procesos de única instancia del CGP y con base en la argumentación aquí expuesta. Se abre el debate sobre la posibilidad en la que los jueces a quienes les corresponde asumir este conoci- miento apliquen estas razones a fin de proveer en forma efectiva una garantía de acceso a la administración de justicia.

\section{Referencias}

Alexy, R. (1997). Teoría de los derechos fundamentales. Madrid: Centro de Estudios Constitucionales.

Arango, R. (2004). Derechos, constitucionalismo y democracia. Serie de Teoría Jurídica y Filosofía del Derecho, 33.

Azula, J. (2008). Manual de derecho procesal civil. Teoría general del proceso. Tomo I. Bogotá: Temis.

Barragán, J. (2003). Decisiones judiciales y desempeño institucional. En: J. Orozco, J. Malem \& R. Vásquez (comps.). La función judicial. Ética y democracia (pp. 181-205). Barcelona: Gedisa.

Bernal, A. (2011). Los derechos humanos procesales, el verdadero objetivo de la oralidad en el proceso civil. Revista Nueva Época, 37, pp. 229-255.

Bernal, C. (2005). El derecho de los derechos. Bogotá: Universidad Externado de Colombia.

Botero, A. (2003). La metodología documental en la investigación jurídica: alcances y perspectivas. Opinión Jurídica: 4, juliodiciembre, pp. 109-116.

Calderón, M. A. (2014). Estado de cosas inconstitucional por omisión en la expedición del estatuto del trabajo en Colombia. Revista Academia \& Derecho, 5(8), pp. 71-97.

Congreso de la República de Colombia. (1991). Constitución Política.

Congreso de la República de Colombia. (2011). Exposición de motivos. Gaceta, 250.

Congreso de la República de Colombia. (2012). Ley 1564. Por medio de la cual se expide el Código General del Proceso y se dictan otras disposiciones. 
Corte Constitucional de Colombia. (1992). Sentencia T-406. M. P.: Eduardo Cifuentes Muñoz.

Corte Constitucional de Colombia. (1993). Sentencia C-345. M. P.: Alejandro Martínez Caballero.

Corte Constitucional de Colombia. (1996). Sentencia C-022. M. P.: Carlos Gaviria Díaz.

Corte Constitucional de Colombia. (1996). Sentencia T-669. M. P.: Alejandro Martínez Caballero.

Corte Constitucional de Colombia. (2002). Sentencia C-131. M. P.: Jaime Córdoba Triviño.

Corte Constitucional de Colombia. (2003). Sentencia C-900. M. P.: Jaime Araujo Rentería.

Corte Constitucional de Colombia. (2004). Sentencia C-154. M. P.: Álvaro Tafur Galvis.

Corte Constitucional de Colombia. (2005). Sentencia C-103. M. P.: Manuel José Cepeda Espinosa.

Corte Interamericana de Derechos Humanos. (2006). Caso Almonacid Arellano y otros us. Chile.

Devis, H. (1999). Compendio de derecho procesal. Tomo I. Teoría general del proceso (12ª ed.). Bogotá: Temis.

Dworkin, R. (1980). ¿Es el derecho un sistema de normas? Ciudad de México: Fondo de Cultura Económica.

García, J. A. (2009). El juicio de ponderación y sus partes. Una crítica. En: R. Alexy (coord.). Derechos sociales y ponderación (pp. 249-326). Madrid: Fundación Coloquio Europeo.

Jaramillo, L. (2012). Comentarios al proyecto de Código General del Proceso. Revista Nueva Época, 38, pp. 27-42.

La Porta, F. J. (2007). El Imperio de la ley. Una visión actual. Madrid: Trotta.
López, H. (1997). Instituciones de derecho procesal civil colombiano (7a ed.). Bogotá: Dupre.

Marinoni, G. (2007). Derecho fundamental a la tutela jurisdiccional efectiva. Lima: Palestra Editores.

Morales, H. (2010). Los presupuestos procesales en el Código de Procedimiento Civil. Revista Nueva Época, 35, pp. 139-150.

Ovalle, J. (2007). Bases constitucionales para un proceso civil justo. XXVIII Congreso Colombiano de Derecho Procesal. Bogotá, Universidad Libre.

Palacios, N. (2012). Análisis jurídico ley 1564 de 2012, sistema general del proceso (SGP) y su incidencia directa con la oralidad, el régimen probatorio y el principio de celeridad procesal. Trabajo de grado para optar al título de abogado. Cali, Universidad de San Buenaventura.

Pérez, A. (2010). Nuevos retos del Estado constitucional: valores, derechos, garantías. Cuadernos Democracia y Derechos Humanos, Serie 2.

Quinche, M. (2014).Vías de hecho. Acción de tutela contra providencias ( $4^{\mathrm{a}}$ ed.). Bogotá: Grupo Editorial Ibáñez.

Ramírez, G. (2003). Los límites a la reforma constitucional y las garantías. Límites del poder constituyente: los derechos fundamentales como paradigma. Bogotá: Universidad Externado de Colombia.

Rodríguez, C. (2011). El derecho en América Latina. Un mapa para el pensamiento jurídico del siglo XXI. Buenos Aires: Siglo Veintiuno Editores, Colección Derecho y Política.

Rojas, M. (2011). Apuntes sobre la ley de descongestión 1395 de 2010 (2a ed.). Bogotá: Doctrina y Ley.

Sánchez, J. (2015). Entre la recepción y la omisión de una obligación internacional: el 
control de convencionalidad en el Consejo de Estado. Revista Academia \& Derecho, 6(11), pp. 183-226.

Sánchez, P. A. (2013). El fin del proceso un asunto cultural: la búsqueda de la verdad o la solución del conflicto. Revista Academia \& Derecho, 4(7), pp. 41-52.

Schmitt, C. (2009). Teología política. Madrid: Trotta.

Taruffo, M. (2007). Consideraciones sobre la teoría chiovendiana de la acción. Revista de Derecho Privado Universidad Externado de Colombia, 9(12-13), pp. 127-139.

Uprimny, R. (2005). Bloque de constitucionalidad, derechos humanos y proceso penal. Bogotá: Consejo Superior de la Judicatura.

Valencia, H. (2007). Nomoárquica, principia- lística jurídica o filosofía y ciencia de los principios generales del derecho ( $4^{a}$ ed.). Medellín: Comlibros.

Yáñez, D. A. (2014). La investigación jurídica: necesidad de la ficha de análisis jurisprudencial en el arte del derecho. En: D. Clavijo, D. Guerra \& D. A. Yáñez. Método, metodología y técnicas de la investigación aplicadas al derecho (pp. 77-103). Bogotá: Grupo Editorial Ibáñez, Universidad de Pamplona.

Yáñez, D. A. \& Yáñez, J. C. (2012). Las fuentes del derecho en la Constitución Política de 1991: una teoría que plantea la existencia de dos jueces distintos. Revista Academia \& Derecho, 3(5), pp. 7-34.

Zagrebelsky, G. (1995). El derecho dúctil. Madrid: Trotta. 